\title{
Effect of estrous cycle phase on vulvar, orbital area and muzzle surface temperatures as determined using digital infrared thermography in buffalo
}

\author{
Felipe Rydygier de Ruediger ${ }^{\mathrm{a}, *}$, Paulo Henrique Yamada ${ }^{\mathrm{a}}$, \\ Luiz Gustavo Bicas Barbosa ${ }^{\mathrm{a}}$, Marcelo George Mungai Chacur ${ }^{\mathrm{b}}$, \\ João Carlos Pinheiro Ferreira ${ }^{a}$, Nelcio Antonio Tonizza de Carvalhoc, \\ Gabriela Azenha Milani Soriano $^{\mathrm{b}}$, Viviane Maria Codognoto ${ }^{\mathrm{a}}$, Eunice $\mathrm{Oba}^{\mathrm{a}}$ \\ a Programa de Pós-Graduação em Biotecnologia Animal, FMVZ, UNESP, Botucatu, SP, Brazil \\ ${ }^{\mathrm{b}}$ Programa de Pós-Graduação em Ciência Animal, UNOESTE Presidente, Prudente, SP, Brazil \\ ${ }^{\mathrm{c}}$ Agência Paulista de Tecnologia dos Agronegócios, APTA, Registro, SP, Brazil
}

\section{A R T I C L E I N F O}

\section{Keywords:}

Digital infrared thermography

Estrous cycle

Progesterone

Weather

\begin{abstract}
A B S T R A C T
The objective of this study was to evaluate variations in the orbital area, muzzle and vulva surface temperatures and progesterone (P4) concentrations during follicular and luteal phases in Murrah buffalo and whether these temperatures are influenced by the weather patterns. Forty cows were submitted to P4-based hormonal protocol. After P4 device withdrawal transrectal ultrasonography and infrared digital thermography were performed daily until day 16 and on days $20,24,28$ and 32 to follow the ovulation as well as the vulva, orbital area and muzzle temperatures. In addition, the weather variables were evaluated, as well as rectal temperature (RT) and P4 and cortisol concentration. Vulva, muzzle and orbital area temperatures correlated positively with RT and with weather data. Greater temperatures of the vulva, orbital area and muzzle were detected during the period of estrus. The vulvar surface temperature (VST) was not influenced to a great extent by weather factors during the morning, so this period was chosen to evaluate the influence of the phase of the estrous cycle on VST. The VST was less during days 16, 20, 24 and 28 (diestrus) and P4 concentration was inversely proportional to the VST. Muzzle, orbital area and RT, however, were not of the same pattern. Negative correlations were observed between VST and P4 concentrations. It is concluded that VST undergoes changes during the reproductive phases, correlating with $\mathrm{P} 4$ concentration. The weather factors influence the temperatures of the body surface areas, and the morning is the most desirable time to perform the thermographies.
\end{abstract}

\section{Introduction}

Fixed-time artificial insemination method (FTAI) has been used in buffalo to enhance selection for animals with superior genetics and greater reproductive rates (Baruselli et al., 2013). Ancillary methods are studied in search of an enhanced efficiency of the FTAI in cattle, and markers can be used to observe which females were produced by the other animals through homosexual behavior

\footnotetext{
* Corresponding author at: Rua Prof. Dr. Walter Mauricio Correa, s/n, Rubião Júnior, Botucatu, São Paulo, 18618-970, Brazil.

E-mail address: f_rydygier@hotmail.com (F.R. de Ruediger).
} 
typical of estrous expression (Sá Filho et al., 2011). In buffalo, homosexual behavior is not expressed, and it is necessary to develop practical methods to identify estrus (Singh et al., 2000; Hockey et al., 2010).

Physiological events, such as the estrous cycle, can alter tissue vascularization and blood flow. The surface of the skin functions as a cooling system that irradiates heat, and the vascular variations of certain tissues possibly alter the surface temperature of the skin (Purohit et al., 1985). Different invasive techniques have been used to measure changes in body temperature during estrus, but these may be influenced by the stress caused to the animal (Clapper et al., 1990; Mosher et al., 1990; Kyle et al., 1998; Redden et al., 1993; Fisher et al., 2008). Infrared digital thermography (IDT) is a non-invasive technology that allows accurate measurement of surface temperature (Chacur et al., 2016a) and has great potential in its applicability in animal reproduction. Few studies, however, have been conducted in this area of research (Ricarte et al., 2014).

The IDT has the potential for use in research, however, the surface temperature of an animal can be affected by ambient temperature, air flow, air humidity and debris on the surface of the skin (Cravello and Ferri, 2008). Generally it is recommended that ambient temperatures be below $30^{\circ} \mathrm{C}$ when monitoring skin surface temperatures (Sykes et al., 2012).

The IDT is experimentally used to monitor and elucidate the heat changes of the animals in the environment; to study scrotal thermoregulation in ruminants (Kastelic et al., 1996; Ruediger et al., 2016); mastitis in dairy cows (Colak et al., 2008); and to analyze changes in the locomotor system of horses (Alsaaod e BüScher, 2012) and ruminants (Stewart et al., 2010). There are reports of the use of IDT to detect changes in vulvar temperatures between estrus and diestrus in sows (Scolari et al., 2011; Sykes et al., 2012), ewes (George et al., 2014) and dairy cows (Talukder et al., 2014).

The applicability of IDT in buffalo has recently been demonstrated. It was verified that the skin temperatures of the orbital area, flank and ears are subject to weather variations and correlated with rectal temperature and can be used in studies of thermal comfort in these animals (Barros et al., 2016; Sevegnani et al., 2016).

Thus, the objectives of this study were to analyze variations of orbital area, muzzle and vulva temperature and variations in progesterone (P4) concentrations, during the follicular and luteal phases of the estrous cycle, as well as to evaluate the influence of weather on the temperatures obtained by IDT in Murrah buffalo treated with a hormonal protocol that was designed to synchronize time of ovulation.

\section{Materials and methods}

After the approval of the research project by the Ethics Committee on the Use of Animals (CEUA 18/2016), data were collected between April and August 2016 in Registro /SP/Brazil, with humid subtropical weather, dry winter, hot and humid summer, a rainy season from October to March and a dry season from April to September.

\subsection{Animals}

A total of 40 Murrah buffalo were used in the study, with a mean \pm SD age of $95.1 \pm 48.2$ months, body condition score of $3.6 \pm 0.3$ (range 1-5), daily milk production of $6.6 \pm 1.2 \mathrm{~kg}$ and $112.5 \pm 55.5$ days in lactation.

\subsection{Feeding}

The animals were submitted to the same nutritional management in rotational grazing (Brachiaria brizantha) with water and mineralized salt ad libitum, and a supply of cereal concentrate before milking.

\subsection{Experimental design}

Synchronization of time of ovulation among the selected animals was performed using a hormonal protocol consisting of the insertion of a P4-releasing intravaginal device (1,0 g, Sincrogest, Ourofino, Cravinhos, SP, Brazil) plus 2 mg of estradiol benzoate (EB, im, Sincrodiol, Ourofino, Cravinhos, SP, Brazil) on the first day of the treatment period (D0). After 9 days (D9), prostaglandin F2 alpha (0150 mg, im, d-cloprostenol, Croniben, Biogéneses Bagó, Buenos Aires, Argentina) and 400 IU of equine chorionic gonadotrophin (eCG, im, Folligon, MSD Saúde Animal, São Paulo, SP, Brazil) were administered, followed by treatment with GnRH (10 $\mu g$ of buserelin acetate, im Sincroforte, Ourofino, Cravinhos, SP, Brazil) on day 11 (D11). Ultrasonography and blood collection were performed daily in the afternoon from D9 to D16 and D20, 24, 28 and 32. The muzzle, orbital area and vulva IDT accompanied by the measurement of weather data were performed on the same days, during the morning and the afternoon (Fig. 1).

\subsection{Infrared digital thermography}

The IDT (Thermovisor E-40, FLIR, Oregon, USA) of the vulva, muzzle and orbital area was performed twice a day, from the 0700 to 0900 and from the 1500 to $1800 \mathrm{~h}$, during all phases of the estrous cycle. The thermographic images were obtained using an emissivity value of $0.98,1 \mathrm{~m}$ away, with the focus of the emitter directed perpendicular to the vulva, and later at a $45^{\circ}$ angle to the muzzle and to the orbital area. The quality of the thermograms was immediately evaluated, and when necessary the procedures were performed again. The thermograms were stored and then transferred to the computer for analysis (Flir Tools Version 5.11.16357.2007, FLIR, Oregon, USA), where vulva, orbital area and muzzle surface mean temperature were obtained according to the demarcations included in Fig. 2. After the thermography, the rectal temperature (RT) was measured with a digital clinical 


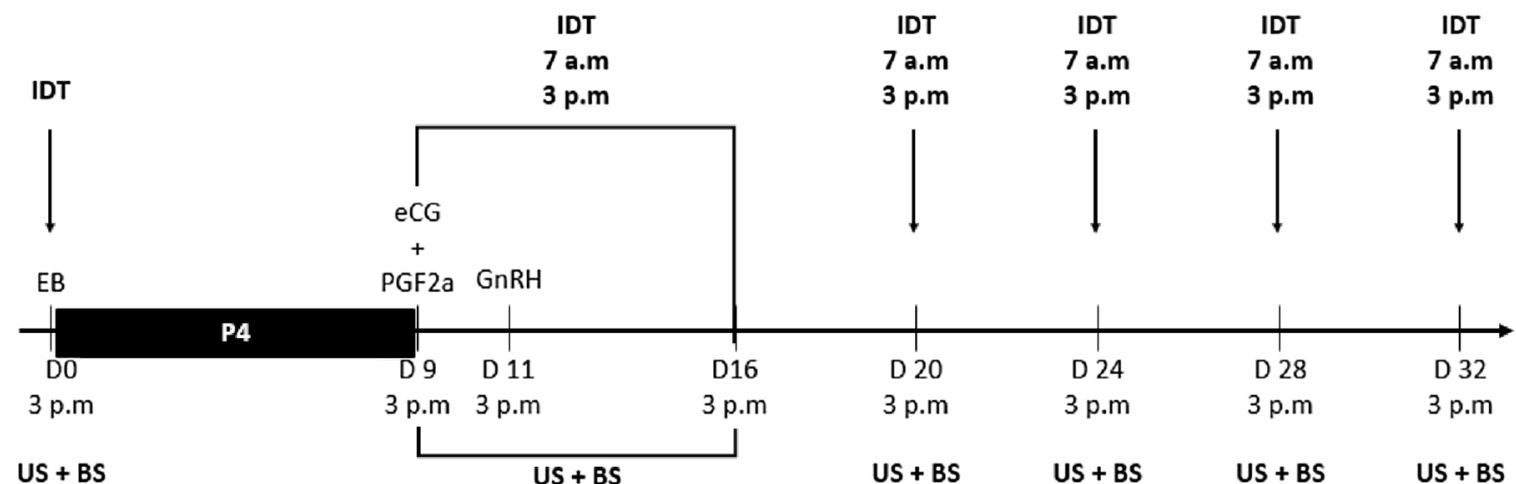

Fig. 1. Timeline of hormonal protocol designed to synchronize of ovulation, vulva, muzzle and orbital area thermography; ultrasonography to follow the ovulation moment; and blood sample for progesterone assay. Intravaginal progesterone device (P4), estradiol benzoate (EB), equine chorionic gonadotropin (eCG), prostaglandin F 2 alpha (PGF2a), gonadotropin releasing hormone (GnRH), ultrasound (US), infrared digital thermography (IDT) and blood sample (BS).
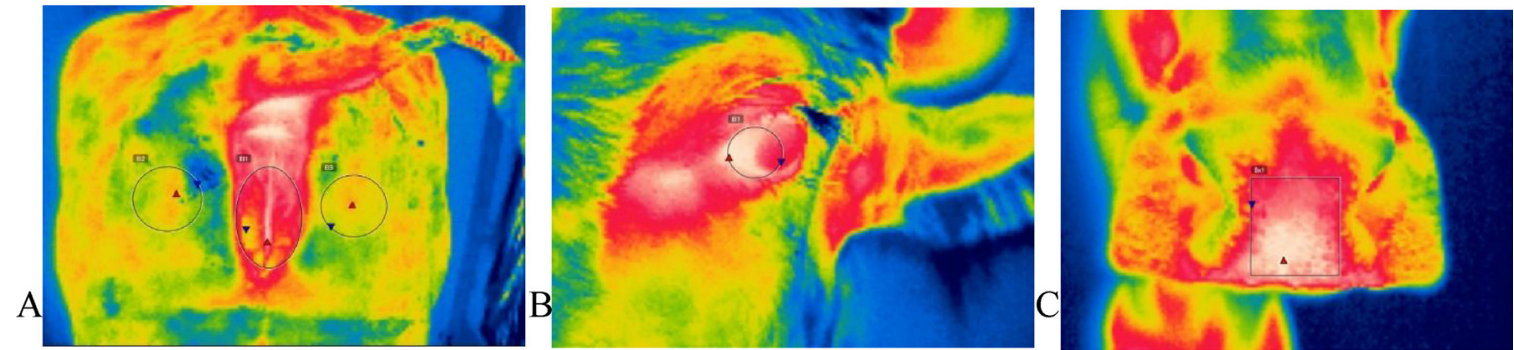

Fig. 2. Thermograms of the vulva (A), orbital area (B) and muzzle (C) of buffalo, with the marked areas of measurement.

thermometer.

\subsection{Weather variables}

The weather data - wet-bulb globe temperature (WBGT), dry-bulb temperature (TA), globe thermometer temperature (TG) and relative humidity $(\mathrm{RH})$ - during the experimental period were recorded hourly using a globe thermometer (ITWTG-2000, InstruTemp $^{\circledast}$, São Paulo, Brazil), as previously described by Stull (2011).

\subsection{Ultrasonography}

Following ovulation, a transrectal mode B ultrasonic assessment was conducted with a $7.5 \mathrm{MHz}$ linear transducer (esaote, MyLab ${ }^{\mathrm{TM}}$ FIVE, Genova, Italy) daily from the 1500 to $1800 \mathrm{~h}$. The time of ovulation was considered to be when the largest follicle was no longer detected and luteal development was also ascertained to be occurring.

\subsection{Blood sampling}

Blood samples were collected from the caudal vein into evacuated tubes containing EDTA. Plasma was subsequently harvested by centrifugation at $2500 \mathrm{~g}$ for $15 \mathrm{~min}$ before being stored in cryotubes at $-20^{\circ} \mathrm{C}$ until the time of assay (Fig. 1).

\subsection{Hormonal assays}

Plasma P4 and cortisol concentrations were measured by radioimmunoassay (Perkin Elmer, 1470 automatic gamma counter, Massachusetts, USA) using commercial solid phase kits (RIA Progesteron IM 1188 and RIA Cortisol IM 1841 Bechman Coulter, California, USA) following the manufacturer's instructions. The sensitivity of the test for P4 was $0.02 \mathrm{ng} / \mathrm{mL}$ and for cortisol $0.04 \mathrm{ng}$ / mL. Intra-assay coefficients of variation were $4.8 \%$ and $5.2 \%$ and the inter-assay coefficients of variation were of $7.5 \%$ and $8.4 \%$ for P4 and cortisol assays, respectively.

\subsection{Statistical analysis}

The statistical analyses were performed using the SAS statistical program (SAS, 2009) through the GLM procedure. The averages 
Table 1

Mean \pm standard error of all data obtained from the mean (SEM) of vulva, muzzle, orbital area surface temperature and rectal temperature (RT) of Murrah buffalo and weather data.

\begin{tabular}{ll}
\hline Temperatures & Mean \pm SEM \\
\hline Vulva surface temperature $\left({ }^{\circ} \mathrm{C}\right)$ & $32.86 \pm 2.86$ \\
Muzzle surface temperature $\left({ }^{\circ} \mathrm{C}\right)$ & $32.11 \pm 3.28$ \\
Orbital area surface temperature $\left({ }^{\circ} \mathrm{C}\right)$ & $35.00 \pm 2.16$ \\
WBGT $\left({ }^{\circ} \mathrm{C}\right)$ & $19.85 \pm 5.26$ \\
TA $\left({ }^{\circ} \mathrm{C}\right)$ & $21.99 \pm 6.45$ \\
TG $\left({ }^{\circ} \mathrm{C}\right)$ & $22.33 \pm 6.75$ \\
RH $(\%)$ & $77.07 \pm 8.05$ \\
RT $\left({ }^{\circ} \mathrm{C}\right)$ & $37.50 \pm 0.74$
\end{tabular}

Wet-bulb globe temperature (WBGT), dry-bulb temperature (TA), globe thermometer temperature (TG) and relative humidity (RH).

were input for ANOVA analyses considering a significance level of 5\% to compare vulva surface temperature, muzzle surface temperature and orbital area surface temperature during the follicular and luteal phases.

Repeated measures statistical analyses were conducted for vulva surface temperature during the morning period and plasma P4 concentration of the animals as a random factor and day as a fixed effect. The model used was $Y_{i j k}=D_{i}+T j+e_{i j k}$, where $Y_{i j k}=$ trait analyzed; $D_{i}=$ fixed effect of day; $\mathrm{Tj}=$ random effect of buffalo; $\mathrm{e}_{\mathrm{ijk}}=$ random error.

Pearson correlations were determined between vulva surface temperature, muzzle surface temperature, orbital area surface temperature and rectal temperature, plasma P4 concentration; between vulva surface temperature, muzzle surface temperature, orbital area surface temperature, RT, WBGT, TA, TG, RH and plasma cortisol concentration; between vulva surface temperature, muzzle surface temperature, orbital area surface temperature, RT and WBGT, TA, TG, RH separately between the morning and afternoon periods and classified according to Levine et al. (2012).

\section{Results}

The mean and standard error of vulva, muzzle and orbital area surface temperature, rectal temperature and weather data obtained during the experimental period are shown in Table 1.

The RT, vulva, muzzle and orbital area surface temperatures were positively correlated, with a medium correlation between vulva, muzzle temperatures and RT, and there was a strong correlation between orbital area temperature and RT (Table 2).

The ovulation occurred $13.6 \pm 1.3$ days of the treatment protocol. Comparing the vulva, muzzle and orbital area surface temperatures means between follicular (days 9, 10, 11, 12, 13 and 32) and luteal phases (days 14, 15, 16, 20, 24 and 28), a greater temperature was observed during the follicular phase (Table 3 ).

During the morning period $(0700$ to $0900 \mathrm{~h})$ there were milder temperatures than the afternoon period (1500-1800 hours) with WBGT $\left(17.7 \pm 4.3^{\circ} \mathrm{C}\right.$ and $\left.20.6 \pm 6.2{ }^{\circ} \mathrm{C}, P=0.003\right)$; TA $\left(18.8 \pm 3.5{ }^{\circ} \mathrm{C}\right.$ and $\left.23.6 \pm 6.7{ }^{\circ} \mathrm{C}, P=0.005\right)$; TG (19.1 $\pm 4.7{ }^{\circ} \mathrm{C}$ and $\left.23.9 \pm 6.3{ }^{\circ} \mathrm{C}, P<0.001\right)$; and $\mathrm{RH}(85.7 \pm 12.2 \%$ and $70.1 \pm 16.7 \%, P=0.001)$, respectively.

Thus, the values for weather data were strongly correlated with values for vulva, muzzle and orbital area surface temperatures, and RT in the morning and afternoon periods, indicating that during the afternoon, the correlations were strong for WBGT, TA and TG and moderate with RH, and in the morning, the correlations were moderate for WBGT, TA and TG and weaker for RH. This indicates that the weather had a greater influence on the vulva, orbital area and muzzle superficial temperatures obtained by thermography during the afternoon (Table 4).

Based on this observation, it was decided to use the vulva, muzzle and orbital area surface temperatures of the morning period for statistical evaluation. In this evaluation, the surface temperatures of the vulva during days 16, 20, 24 and 28 of the experimental design were less in relation to days $9,10,11,12,13,14,15$ and 32, being followed by inversely proportional values of the plasma P4 concentration as depicted in Fig. 3. The orbital area and muzzle surface temperatures, however, did not follow the same pattern of vulvar temperature variation.

In addition, strong negative correlations were observed between vulva surface temperatures and plasma P4 concentration, and

Table 2

Pearson correlation coefficient and significance level $(P)$ between rectal temperature (RT) and vulva, muzzle and orbital area surface temperatures, obtained by infrared digital thermography in Murrah buffalo.

\begin{tabular}{llr}
\hline Variable & RT & $P$ \\
\hline Vulva surface temperature & 0.69 & $<0.001$ \\
Muzzle surface temperature & 0.69 & $<0.001$ \\
Orbital area surface temperature & 0.77 & $<0.001$ \\
\hline
\end{tabular}


Table 3

Mean \pm standard error of the mean (SEM) and significance level $(P)$ of vulva, muzzle and orbital area surface temperatures, obtained by infrared digital thermography, compared between follicular and luteal phases of Murrah buffalo.

\begin{tabular}{lrr} 
Temperature & $\begin{array}{l}\text { Follicular } \\
\text { Mean } \pm \text { SEM }\end{array}$ & $\begin{array}{l}\text { Luteal } \\
\text { Mean } \pm \text { SEM }\end{array}$ \\
\hline Vulva surface temperature $\left({ }^{\circ} \mathrm{C}\right)$ & $33.67 \pm 2.86$ & $31.68 \pm 2.86$ \\
Muzzle surface temperature $\left({ }^{\circ} \mathrm{C}\right)$ & $33.25 \pm 3.26$ & $30.69 \pm 3.28$ \\
Orbital area surface temperature $\left({ }^{\circ} \mathrm{C}\right)$ & $35.72 \pm 2.15$ & $33.93 \pm 2.15$ \\
\hline
\end{tabular}

\section{Table 4}

Pearson correlation coefficients between weather data and vulva, muzzle and orbital area surface temperatures and rectal temperature (RT) of buffalo during the morning and afternoon.

\begin{tabular}{|c|c|c|c|c|c|c|c|c|}
\hline \multicolumn{5}{|l|}{ Afternoon } & \multicolumn{4}{|c|}{ Morning } \\
\hline Variable & WBGT & TA & TG & RH & WBGT & TA & TG & RH \\
\hline Vulva surface temperature & $0.83^{*}$ & $0.82^{*}$ & $0.83^{*}$ & $0.46^{*}$ & $0.50^{*}$ & $0.40^{*}$ & $0.50^{*}$ & $0.91^{* *}$ \\
\hline Muzzle surface temperature & $0.86^{*}$ & $0.84^{*}$ & $0.82^{*}$ & $0.53^{*}$ & $0.52^{*}$ & $0.52^{*}$ & $0.52^{*}$ & 0.10 \\
\hline Orbital area surface temperature & $0.86^{*}$ & $0.83^{*}$ & $0.83^{*}$ & $0.63^{*}$ & $0.54^{*}$ & $0.57^{*}$ & $0.58^{*}$ & 0.11 \\
\hline RT & $0.82^{*}$ & $0.79^{*}$ & $0.81^{*}$ & $0.61^{*}$ & $0.53^{*}$ & $0.57^{*}$ & $0.54^{*}$ & 0.03 \\
\hline
\end{tabular}

${ }^{*} P<0,001{ }^{* *} P<0.05$; Wet-bulb globe temperature (WBGT), dry-bulb temperature (TA), globe thermometer temperature (TG) and relative humidity (RH).

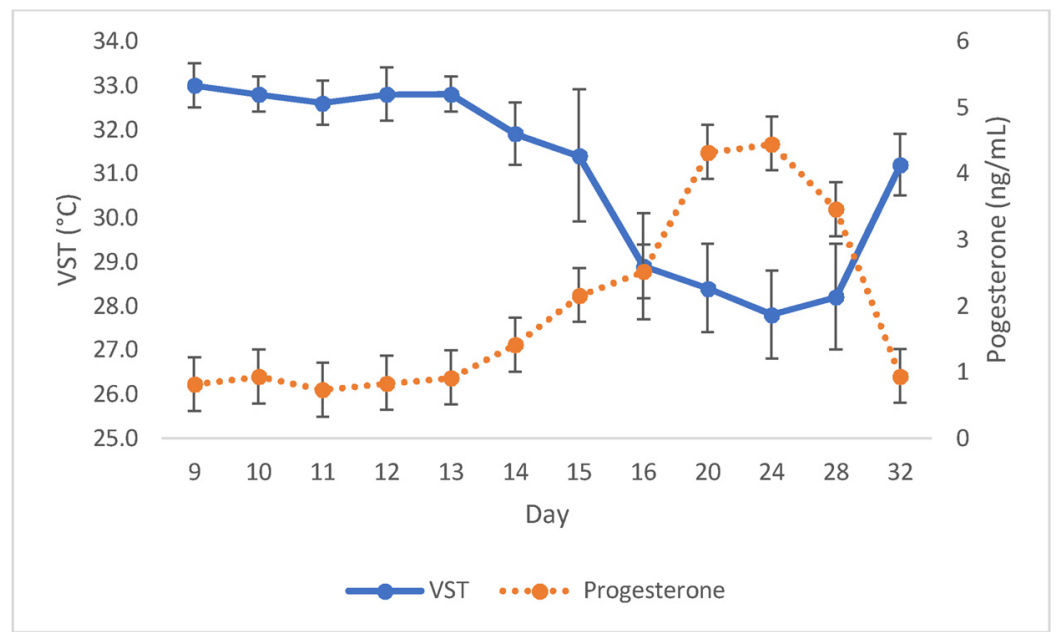

Fig. 3. Variation of the vulva surface temperature (VST) and plasma progesterone concentration during the days of the experiment in buffalo.

weak negative correlations were observed between plasma P4 concentration and surface temperatures of the muzzle and orbital area (Table 5).

Cortisol plasma concentrations ranged from 2.84 to $0.69 \mathrm{ng} / \mathrm{mL}$ and were moderately to strongly correlated with vulva, muzzle and orbital area surface temperatures. There was also a positive correlation between plasma cortisol concentrations and RT and values for weather data, indicating that the hotter and more humid the environment in which the animals were residing, the greater the surface temperatures and RT, with an increase in plasma cortisol concentration being observed that was coincident with these changes (Table 6).

Table 5

Pearson correlation coefficients and significance level $(P)$ between plasma progesterone concentrations and vulva, muzzle, orbital area surface temperatures and rectal temperatures (RT) in buffalo.

\begin{tabular}{llc}
\hline Variable & Progesterone & $P$ \\
\hline Vulva surface temperature & -0.70 & $<0.001$ \\
Muzzle surface temperature & -0.24 & $<0.001$ \\
Orbital area surface temperature & -0.29 & $<0.001$ \\
RT & -0.29 & $<0.001$
\end{tabular}


Table 6

Pearson correlation coefficients and significance level $(P)$ between values for plasma cortisol concentrations and vulva, muzzle and orbital area surface temperatures and rectal temperatures (RT) of Murrah buffalo and values for weather data.

\begin{tabular}{llc}
\hline Variable & Cortisol & $P$ \\
\hline Vulva surface temperature & 0.42 & 0.030 \\
Muzzle surface temperature & 0.54 & 0.010 \\
Orbital area surface temperature & 0.69 & 0.014 \\
RT & 0.69 & 0.011 \\
WBGT & 0.66 & $<0.001$ \\
TA & 0.67 & $<0.001$ \\
TG & 0.60 & $<0.001$ \\
RH & 0.65 & $<0.001$
\end{tabular}

Wet-bulb globe temperature (WBGT), dry-bulb temperature (TA), globe thermometer temperature (TG) and relative humidity (RH).

\section{Discussion}

The vulva, muffle and orbital area surface temperatures (measured by IDT) and the rectal temperatures obtained in the present study are similar to previous studies in dairy cows (Talukder et al., 2014; Chacur et al., 2016b) and dairy buffalo (Barros et al., 2016; Sevegnani et al., 2016). Thus, the IDT technique is of potential applicability in the study of the physiological modifications of body temperature in buffalo.

The IDT from different regions of the body can be studied reliably, reflecting the rectal temperature in a quick, precise and less invasive manner, because the skin functions as a cooling system, radiating temperature, as demonstrated in the present study, where moderate to strong correlations occurred between RT and vulva, and muzzle and orbital area surface temperatures. In a recent study with dairy buffalo (Barros et al., 2016; Sevegnani et al., 2016) and Holstein dairy cows (Hoffmann et al., 2013), orbital area and ear surface temperatures were highly correlated with rectal temperatures. It is possible to study the influence of the weather and the hormonal variations inherent to the estrous cycle on these temperatures.

Climatic variations can affect maintenance of the body surface temperature as well as the RT in Nellore bulls (Ruediger et al., 2016), dairy cows (Chacur et al., 2016a), goats (Ricarte et al., 2014) and buffalo (Sevegnani et al., 2016). In this study, when correlating the weather variables (WBGT, TA, TG and UR) with different body region surface temperatures and with the RT, the data were strongly correlated between weather factors and body and rectal temperatures in the afternoon, when the temperature was warmer, and there was a moderate correlation in the morning, when there were milder temperatures (Nabenishi et al., 2011; Talukder et al., 2014). The ideal ambient temperature suggested for obtaining the thermal images at the surface temperature of the skin is near $20^{\circ} \mathrm{C}$ (Sykes et al., 2012).

To achieve desirable conception rates with the use of FTAI, it is possible to use estrous detection in an auxiliary way (Sá Filho et al., 2011). In buffalo, there is a relationship between the size of the largest ovarian follicle at the time of artificial insemination with the ovulation rate and later with the pregnancy rate of these animals (Baruselli et al., 2013; Carvalho et al., 2013). In search of new techniques to aid in the detection of oestrus, Osawa et al. (2004) studied the variations of vulva temperatures in cows and observed an increase in vulvar surface temperature of cows in estrus compared with the diestrus periods and Sykes et al. (2012) noted the same phenomenon in sows. The same occurred in the present experiment, with a greater temperature not only of the vulva but also of the muzzle and the orbital area during the preovulatory period in relation to the diestrus period (Table 3).

The variation in the vulva surface temperature that occurred in the present study is probably due to variation in the blood concentrations of progesterone and estrogen that occur during the estrous cycle, which can lead to a variation of blood circulation in the vulva (Fig. 3) (Scolari et al., 2011; Talukder et al., 2014). Thus, in the present study there were strong negative correlations between the plasma P4 concentration and the vulva surface temperature, corroborating with the hypothesis for the previous study that the vulva surface temperature decreases when there is an increase in the plasma P4 concentration, as well as the hypothesis proposed by Sykes et al. (2012).

Talukder et al. (2014), using dairy cows, and Simões et al. (2014), studying gilts, observed the same pattern of the vulvar surface temperature variation during the estrous cycle that occurred in the present study (Fig. 3), but both found a vulvar surface temperature peak $48 \mathrm{~h}$ before ovulation, which was not observed in the present study, probably due to the use of buserelin acetate on the 11th day of the hormonal protocol for ovulation induction, which may have affected the physiological system for ovulation by altering the vulvar temperature pattern.

In the present experiment, the same pattern of variation of the vulva surface temperature was not observed for the muzzle, orbital area surface temperatures and RT day-to-day. Talukder et al. (2014), however, reported that there was a muzzle surface temperature variation following the vulva surface temperature variation during the estrous cycle of the animals in this previous study. This inconsistency may have been observed because the animals in the present study were located in an area where there were tropical weather conditions with the animals in the field which was different from the type of environment that the animals were located in the previous study of Talukder et al. (2014). In the previous study, free stall cows, probably resulting in a lesser climate effect on the temperature of the muzzle, thus allowing for the assessment of the muzzle thermographic pattern resulting from the hormonal 
variations inherent to ovulation.

Although there was not an efficacy of the diagnosis of estrus, the values for orbital area and muzzle surface temperatures were correlated with the rectal temperature, as well as values for weather data and plasma cortisol concentrations (Table 6). Changes in the orbital area and muzzle surface temperatures accompanied by weather variations can be explained by heat dissipation to the environment as a result of vasodilation and increased blood flow to peripheral tissues of the body (Titto et al., 1998; Silanikove, 2000; Marai and Haeeb, 2010). Buffalo are more susceptible to weather change and thermal stress, because of the darker colored body and a relatively smaller number of sweat glands (Gudev et al., 2007; Marai et al., 2009; Marai and Haeeb, 2010). Furthermore, thermal stress can cause changes in the plasma cortisol concentration (Christison and Johnson, 1972; Leining et al., 1980; Nessim, 2004), leading to losses in the productive and reproductive efficiencies of the herds (Barros et al., 2016; Chacur et al., 2016b; Sevegnani et al., 2016). Thus, surface thermography of these areas of the body can be used in the study of thermal comfort of dairy buffalo.

\section{Conclusions}

The vulvar superficial temperature is effective in ascertaining the physiological changes inherent to the progesterone concentration variation during the reproductive cycle of buffalo. The muzzle and orbital area superficial temperatures were not consistent with changes in the vulvar superficial temperature in relation to the variations of the estrous cycle but did correlate with RT and weather factors. For standardization of the techniques used in the present study, other studies on the use of IDT as a complementary technique in the reproductive examination and evaluation of animal welfare of buffalo are recommended.

\section{Declarations of interest}

None.

\section{Acknowledgments}

The authors thank APTA-Vale do Ribeira and UNESP-Botucatu for allowing the use of their animals and of their structure for this study, and also thank FAPESP, CAPES and CNPq for their financial support.

\section{References}

Alsaaod, M., Büscher, W., 2012. Detection of hoof lesions using digital infrared thermography in dairy cows. J. Dairy Sci. 95, 735-742.

Barros, D.V., Silva, L.K.X., Kahwage, P.R., Lourenço Jr, J.B., Sousa, J.S., Silva, A.G.M., Franco, I.M., Martorano, L.G., Garcia, A.R., 2016. Assessment of surface temperatures of buffalo bulls (Bubalus bubalis) raised under tropical conditions using infrared thermography. Arquivo Brasileiro de Medicina Veterinária e Zootecnia. 68, 422-430.

Baruselli, P.S., Soares, J.G., Gimenes, L.U., Monteiro, B.M., Olazarri, M.J., Carvalho, N.A.T., 2013. Control of buffalo follicular dynamics for artificial insemination, superovulation and in vitro embryo production. Buff. Bull. 32, 160-176.

Carvalho, N.A.T., Soares, J.G., Porto Filho, R.M., Gimenes, L.U., Souza, D.C., Nichi, M., Sales, J.S., Baruselli, P.S., 2013. Equine chorionic gonadotropin improves the efficacy of a timed artificial insemination protocol in buffalo during the nonbreeding season. Theriogenology 79, $423-428$.

Chacur, M.G.M., Bastos, G.P., Vivian, D.S., Silva, L., Chiari, L.N.F., Araujo, J.S., Souza, C.D., Gabriel Filho, L.R.A., 2016a. Use of infrared thermography to evaluate the influence of the of climatic factors in the reproduction and lactation of dairy cattle. Acta Sci. Vet. 44, 1412-1421.

Chacur, M.G.M., Souza, C.D., Bastos, G.P., Gabriel Filho, L.R.A., Cremasco, C.P., Putti, F.F., 2016b. Fatores climáticos e bem-estar em bovinos: enfoque na reprodução e lactação. In: Silva, A.L.C., Benini, S.M., Dias, L.S. (Eds.), Org.), Fórum Ambiental - Uma visão multidiscipiinar da questão ambiental, second ed. ANAP, Brasil, pp. 253-270.

Christison, G.I., Johnson, H.D., 1972. Cortisol turnover in heat stressed cows. J. Anim. Sci. 35, 1005-1010.

Clapper, J.A., Ottobre, J.S., Ottobre, A.C., Zartman, D.L., 1990. Estrual rise in body temperature in the bovine I. Temporal relationships with serum patterns of reproductive hormones. Anim. Reprod. Sci. 23, 89-98.

Colak, A., Polat, B., Okumus, Z., Kaya, M., Yanmaz, L.E., Hayirli, A., 2008. Short communication: early detection of mastitis using infrared thermography in dairy cows. J. Dairy Sci. 91, 4244-4248.

Cravello, B., Ferri, A., 2008. Relationships between skin properties and environmental parameters. Skin Res. Technol. 14, 180-186.

Fisher, A.D., Morton, R., Dempsey, J.M., Henshall, J.M., Hill, J.R., 2008. Evaluation of a new approach for the estimation of the time of the LH surge in dairy cows using vaginal temperature and electrodeless conductivity measurements. Theriogenology 70, 1065-1074.

George, W.D., Godfrey, R.W., Ketring, R.C., Vinson, M.C., Willard, S.T., 2014. Relationship among orbital area and muzzle temperatures measured using digital infrared thermal imaging and vaginal and rectal temperatures in hair sheep and cattle. J. Anim. Sci. 92, 4949-4955.

Gudev, D., Popova-Ralcheva, S., Moneva, P., Aleksiev, Y., Peeva, T., Ilieva, Y., Penchev, P., 2007. Effect of heatstress on some physiological and biochemical parameters in buffaloes. Ital. J. Anim. Sci. 6, 1325-1328.

Hockey, C.D., Morton, J.M., Norman, S.T., Mcgowan, M.R., 2010. Evaluation of a neck mounted 2-hourly activity meter system for detecting cows about to ovulate in two paddock-based Australian dairy herds. Reprod. Domest. Anim. 45, 107-117.

Hoffmann, G., Schmidt, M., Ammon, C., Rose-Meierhöfer, S., Urfeind, O., Heuwieser, W., 2013. Monitoring the body temperature of cows and calves using video recordings from an infrared thermography camera. Vet. Res. Comm. 37, 91-99.

Kastelic, J.P., Cook, R.B., Coulter, G.H., Wallins, G.L., Entz, T., 1996. Environmental factors affecting measurement of bovine scrotal surface temperature with infrared thermography. Anim. Reprod. Sci. 41, 153-159.

Kyle, B.L., Kennedy, A.D., Small, J.A., 1998. Measurement of vaginal temperature by radiotelemetry for the prediction of estrus in beef cows. Theriogenology 49 1437-1449.

Leining, K.B., Tucker, A.H., Kesner, J.S., 1980. Growth Hormone, Glucocorticoid and Thryoxine Response to Duration, Intensity and Wavelength of Light in Prepubertal Bulls. Am. Soc. Anim. Sci. 51, 932-942.

Levine, D.M., Berenson, M.L., Stephan, D., 2012. Estatística: Teoria e Aplicações, 6th ed. LTC, Rio de Janeiro, RJ.

Marai, I.F.M., Haeeb, A.A.M., 2010. Buffalo's biological functions as affected by heat stress - a review. Livestock Sci. 127, 89-109.

Marai, I.F.M., Daader, A.H., Soliman, A.M., El-Menshawy, S.M.S., 2009. Non-genetic factors affecting growth and reproduction traits of buffloes under dry management housing in Egypt. Livest. Res. Rural Dev. 21, 1-13.

Mosher, M.D., Ottobre, J.S., Haibel, G.K., Zartman, D.L., 1990. Estral rise in body temperature in the bovine II. The temporal relationship with ovulation. Anim. 
Reprod. Sci. 23, 99-107.

Nabenishi, H., Ohta, H., Nishimoto, T., Morita, T., Ashizawa, K., Tsuzuki, Y., 2011. Effect of the temperature-humidity index on body temperature and conception rate of lactating dairy cows in southwestern Japan. J. Reprod. Dev. 57 (4), 450-456.

Nessim, M.G., 2004. Heat-induced Biological Changes as Heat Tolerance Indices Related to Growth Performance in Buffaloes. Ph.D. Thesis. Faculty of Agriculture, Ain Shams University, Cairo, Egypt.

Osawa, T., Tanaka, M., Morimatsu, M., Hashizume, K., Syuto, B., 2004. Use of infrared thermography to detect the change in the body surface temperature with estrus in the cow. Proceedings from the Society for Theriogenology Annual Conference.

Purohit, R.C., Hudson, R.S., Riddell, M.G., Carson, R.L., Wolfe, D.F., Walker, D.F., 1985. Thermography of the bovine scrotum. Am. J. Vet. Res. 46, $2388-2392$.

Redden, K.D., Kennedy, A.D., Ingall, S.J.R., Gilson, T.L., 1993. Detection of estrus by radiotelemetric monitoring of vaginal and ear skin temperature and pedometer measurements of activity. J. Dairy Sci. 76, 713-721.

Ricarte, A.R.F., Façanha, D.A.E., Costa, L.L.M., 2014. Possibilidades na utilização da termografia infravermelha no diagnóstico reprodutivo de caprinos. Acta Veterinaria Brasilica. 8 (2), 380-384.

Ruediger, F.R., Chacur, M.G.M., Alves, F.C.P.E., Oba, E., Ramos, A.A., 2016. Digital infrared thermography of the scrotum, semen quality, serum testosterone levels in Nellore bulls (Bos taurus indicus) and their correlation with climatic factors. Semina Ciências Agrárias. 37, $221-232$.

Sá Filho, M.F., Santos, J.E.P., Ferreira, R.M., Sales, J.N.S., Baruselli, P.S., 2011. Importance of estrus on pregnancy submitted to estradiol/progesterone-based timed insemation protocols. Theriogenology 76 466-463.

SAS Institute, 2009. Statistical Analysis System. Version 9.2. SAS Institute Inc., Cary, NC.

Scolari, S.C., Clark, S.G., Knox, R.V., 2011. Vulvar skin temperature changes significantly during estrus in swine as determined by digital infrared thermography. J. Swine Health Prod. 19, 151-155.

Sevegnani, K.B., Fernandes, D.P.B., Silva, S.H.M.G., 2016. Evaluation of thermorregulatory capacity of dairy buffaloes using infrared thermography. Engenharia Agrícola. 36 (1), 1-12.

Silanikove, N., 2000. Effects of heat stress on the welfare of extensively managed domestic ruminants. Livest. Prod. Sci. 67, 1-18.

Simões, V.G., Lyazrhi, F., Picard-Hagen, N., Gayrard, V., Martineau, G.P., Waret-Szkuta, A., 2014. Variations in the vulvar temperature of sows during proestrus and estrus as determined by infrared thermography and its relation to ovulation. Theriogenology 82, 1080-1085.

Singh, J., Nanda, A.S., Adams, G.P., 2000. The reproductive pattern and efficiency of female buffaloes. Anim. Reprod. Sci. 60/61, 593-604.

Stewart, M., Webster, J.R., Stafford, K.J., Schaefer, A.L., Verkerk, G.A., 2010. Technical note: effects of an epinephrine infusion on eye temperature and heart rate variability in bull calves. J. Dairy Sci. 93, 5252-5257.

Stull, R., 2011. Wet-bulb temperature from relative humidity and air temperature. Am. Meteorol. Soc 50, $2267-2269$.

Sykes, D.J., Couvillion, J.S., Cromiak, A., Bowers, S., Schenck, E., Crenshaw, M., 2012. The use of digital infrared thermal imaging to detect estrus in gilts. Theriogenology 78, 147-152.

Talukder, S., Kerrisk, K.L., Ingenhoff, L., Thomson, P.C., Garcia, S.C., Celia, P., 2014. Infrared technology for estrus detection and as a predictor of time of ovulation in dairy cows in a pasture-based system. Theriogenology 81, 925-935.

Titto, E.A.L., Velloso, L., Zanetti, M.A., Cresta, A., Toledo, L.R.A., Martins, J.H., 1998. Teste da tolerância ao calor em novilhos nelore e marchigiana. Revista Portuguesa de Zootecnia. 5 (1), 67-70. 